\title{
IMPACTOS DA PARTICIPAÇÃO POPULAR NA IV CONFERÊNCIA DA IGUALDADE RACIAL EM RIO GRANDE (RS)
}

\author{
Marcel Jardim Amaral \\ Vilmar Alves Pereira \\ Laís Braga Costa ${ }^{(*)}$
}

O Brasil, último país a abolir a escravidão é marcado por uma profunda vulnerabilidade e/ou miserabilidade étnica e social. Umas das causas para esse fato foram às deficitárias leis préabolicionistas adotadas no decorrer do processo escravocrata e pós a Lei Áurea de 1888.

Embora Camargo e Silva (2013, p.2) lembrem que no governo do ex-presidente Fernando Henrique Cardoso "as políticas públicas de caráter multiculturalista começaram a ser implantadas”; o autor deste artigo ressalta que só a partir de 2003, na gestão do atual preso político ${ }^{1}$ Luís Inácio Lula da Silva é que houve diretamente a intensificação de ações reparadoras em virtude das consequências causadas pelo passado histórico da comunidade negra.

Nos diversos "espaçostempos" educativos da atualidade, estão em destaque as Conferências de Promoção da Igualdade Racial, pois estas são instrumentos que propiciam maior participação da população no que tange a construção e elaboração de políticas públicas. Além disso, concentra diversidades culturais para o debate, com a participação dos indígenas, quilombolas, ciganos, etc.; cada grupo com sua identidade e intencionalidade para a formulação e estratégias que garantam direitos e a valorização cultural. Para o antropólogo Kabengele Munanga:

\footnotetext{
${ }^{(*)}$ Marcel Jardim Amaral. Mestrando em Educação pelo Programa de Pós-Graduação (PPGEDU) da Universidade Federal do Rio Grande (FURG), Linha de pesquisa: Culturas, Identidades e Diferenças. Bolsista da Coordenação de Aperfeiçoamento de Pessoal de Nível Superior (CAPES); e membro do Grupo de Estudos sobre Fundamentos da Educação Ambiental e Popular (GEFEAP), onde faz parte da coordenação do Programa de Auxílio ao Ingresso nos Ensinos Técnico e Superior (PAIETS) Indígena e Quilombola. E-mail: amaral.marcel@ yahoo.com.

Vilmar Alves Pereira. Doutor em Educação, professor e pesquisador no Instituto de Educação. Membro do corpo docente no Programa de Pós-Graduação em Educação (PPGEDU/FURG), Linha de pesquisa: Culturas, Identidades e Diferenças e no Programa de Pós Graduação em Educação Ambiental - Linha de pesquisa: Fundamentos da Educação Ambiental (PPGEA/FURG), do qual é Coordenador. Líder do Grupo de Estudos sobre Fundamentos da Educação Ambiental e Popular (GEFEAP). E-mail: vilmar1972@gmail.com.

Laís Braga Costa. Mestre em Práticas Socioculturais e Desenvolvimento Social pelo Programa de Pós-graduação (PPGPSDS) da Universidade de Cruz Alta (UNICRUZ). Bibliotecária do Instituto Federal Farroupilha - Campus São Vicente do Sul. E-mail: lais.costa@iffarroupilha.edu.br.

${ }^{1} \mathrm{O}$ autor deste artigo usa a expressão "preso político", visto que em sua concepção o julgamento teria assimilações ao tribunal de exceção. Além disso, anterior ao julgamento o ex-presidente manifestou o desejo de candidatar-se novamente à Presidência da República, onde realizou dura crítica ao judiciário brasileiro e por consequência teve o pedido de habeas corpus negado em todas as instâncias.
} 
A identidade é uma realidade sempre presente em todas as sociedades humanas. Qualquer grupo humano, através do seu sistema axiológico sempre selecionou alguns aspectos pertinentes de sua cultura para definir-se em contraposição ao alheio. A definição de si (autodefinição) e a definição dos outros (identidade atribuída) têm funções conhecidas: a defesa da unidade do grupo, a proteção do território contra inimigos externos, as manipulações ideológicas por interesses econômicos, políticos, psicológicos, etc. (MUNANGA, 1994: 177-178).

Vale ressaltar que a participação popular não ocorre apenas em conselhos e conferências; pois é evidente que esta pode vir a acontecer no cotidiano desses sujeitos, através dos movimentos sociais populares em que estes possam estar inseridos, nas suas comunidades tradicionais ou nos grupos populacionais, além do espaço da educação formal. De outro lado, é preciso destacar que a participação do povo se dá legalmente apenas através desses conselhos e conferências, visto que essas ferramentas atuam diretamente na criação de artifícios, no controle da execução de programas de governo e políticas de estado voltadas as minorias, já que é este um espaço de encaminhamento ao poder executivo das demandas apresentadas por estas.

A Política de Promoção da Igualdade Racial foi criada no primeiro mandato do governo de Luiz Inácio Lula da Silva eleito pelo Partido dos Trabalhadores (PT) visto a pressão dos movimentos sociais populares dos diversos segmentos, embora o movimento negro tenha sido protagonista nesta pauta. Nesta conjuntura, mesmo que o plano nacional de redução da discriminação racial seja recente; as três Conferências de Promoção da Igualdade Racial anteriores foram um marco para a história do país que contou com representantes da população negra, indígena, cigana e demais grupos étnicos socialmente discriminados no país.

Como qualquer outra conferência de importante intervenção popular para a criação, formulação e/ou execução de políticas públicas, pode-se dizer que esse espaço com diversas pautas, eixos temáticos e segmentos da sociedade são os principais instrumentos que conduzem a democracia no mundo contemporâneo. Através das conferências, o governo federal visa proporcionar o debate público para o fortalecimento e o incentivo da equidade racial, haja visto que o racismo no Brasil persevera fragilizando brutalmente o progresso e a democracia.

Neste sentido, o governo do estado do Rio Grande do Sul enviou através de sua comissão estadual o regimento interno aos municípios solicitando que o Conselho Municipal de Promoção da Igualdade Racial ou o Conselho Municipal do Negro local estivessem à frente da articulação da Conferência Municipal. Ressalta-se que no caso de regiões municipais que não possuam estes 
Conselhos, o executivo através de suas secretarias de competência, fica então responsável por sua execução e organização.

Sabe-se que para os sujeitos militantes do movimento negro, demais movimentos sociais populares, e funcionários públicos que estejam interessados a participarem como delegados ${ }^{2}$ da IV Conferência Nacional de Promoção da Igualdade Racial, na capital federal do Brasil, existem algumas etapas preparatórias em todos os municípios e/ou regiões do país. Para isso, a comissão organizadora nacional fica então responsável pela tiragem das regras gerais para que o andamento da Conferência possa ser iniciado nos territórios e assim sucessivamente emite o regimento interno do evento contendo atribuições e prazos para o envio das propostas que serão de extrema responsabilidade das comissões estaduais.

Este artigo terá como princípio norteador deste estudo os preceitos do método pesquisaparticipante, pois de acordo com Brandão (1984):

[...] um enfoque de investigação social por meio do qual se busca plena participação da comunidade na análise de sua própria realidade, com objetivo de promover a participação social para o benefício dos participantes da investigação. Estes participantes são os oprimidos, os marginalizados os explorados. Trata-se, portanto, de uma atividade educativa de investigação e ação social.

Enfoque de investigação social, haja visto que o autor deste presente artigo é sujeito ativocrítico, por se tratar de membro da comissão organizadora municipal da Conferência de Promoção da Igualdade Racial Intermunicipal e redator do Conselho Municipal do Desenvolvimento Social e Cultural da Comunidade Negra (COMDESCCON). Além disso, foi nomeado pela plenária, delegado da Conferência Estadual que ocorreu entre os dias 28, 29 e 30de novembro do ano de 2017.

O propósito deste estudo visa possibilitar ao leitor, breve análise da importância da participação popular na IV Conferência Intermunicipal de Promoção da Igualdade Racial, bem como relatar o processo de formulação e discussão dos eixos temáticos, finalizando por fim com os resultados do término da discussão dos grupos de trabalhos (GT's) para o envio das propostas à Conferência Estadual.

\footnotetext{
${ }^{2}$ Cidadão eleito pela plenária na Conferência que tem direito a voz (discussão das temáticas) e direito ao voto (votar as questões que estão sendo debatidas).
} 


\section{A DÉCADA INTERNACIONAL DOS AFRODESCENDENTES (2015/2024)}

No Brasil, mais da metade dos homens e mulheres se autodeclaram pretos ou pardos, porém mesmo em maioria populacional perseveram sendo parte da população que possui acesso limitado aos serviços sociais de qualidade, bem como aos postos de decisão e/ou ascensão social. Além disso, recai sobre essa etnia a fragilidade do judiciário, da intolerância religiosa, do genocídio da juventude e a violência policial. Jéferson Bacelar lembra que ainda hoje:

[...] ao tratarmos da identidade étnica dos negros, ressaltamos que a característica física dos grupos e dos indivíduos, sobremodo a cor, mantém-se como elemento denotador dos seus limites, uma fonte permanente de distinção. Ela é sempre um componente para a estigmatização, desigualdade de indivíduos e grupo, tabus e sanções, estados afetivos e preconceitos. A cor da pele tem servido como insígnia de escravidão e liberdade, da dominação e sujeição (BACELAR, 1989, p.77).

Nesta conjuntura, a Organização das Nações Unidas - ONU no ano de 2015 chamou a atenção do mundo inteiro ao anunciar que até o final do ano de 2024 os países deverão refletir sobre a "Década Internacional dos Afrodescendentes", onde visa celebrar a importante contribuição que a população negra trouxe para a humanidade. Em outras palavras, podemos dizer que a ONU está preocupada em sensibilizar os órgãos competentes para a efetiva aplicação de políticas e ações que amenizem a desigualdade racial, visando então parcerias com os países no mundo inteiro para possível melhoria das condições que hoje se apresentam, quando relacionamos a questão dos afrodescendentes. Conforme Paulo Freire:

O que acontece é que a luta é uma categoria histórica e social. Tem, portanto, historicidade. Muda de tempo-espaço. A luta não nega a possibilidade de acordos, de acertos entre as partes antagônicas [...]. Há momentos históricos em que a sobrevivência do todo social, que interessa às classes sociais, lhes coloca a necessidade de se entenderem, o que não significa estarmos vivendo um novo tempo, vazio de classes e conflitos. (FREIRE, 1994, p. 43)

A década destinada a esse grupo étnico, alerta também que ainda há extrema necessidade de que os países busquem enfrentar o racismo, a discriminação racial e a intolerância, destacando que o reconhecimento, a justiça e o desenvolvimento devem ser vistas como prioridades mundiais. No Brasil, a Década Internacional dos Afrodescendentes foi lançada no dia 22 de Julho de 2015, no Festival da Mulher Afro Latino Americana e Caribenha, evento este que visa buscar dar visibilidade às trajetórias e lutas das mulheres negras no evento e fora dele. 
Figura 1. Logo da Década Internacional de Afrodescendentes

Fonte: http://decada-afro-onu.org/logos.shtml>

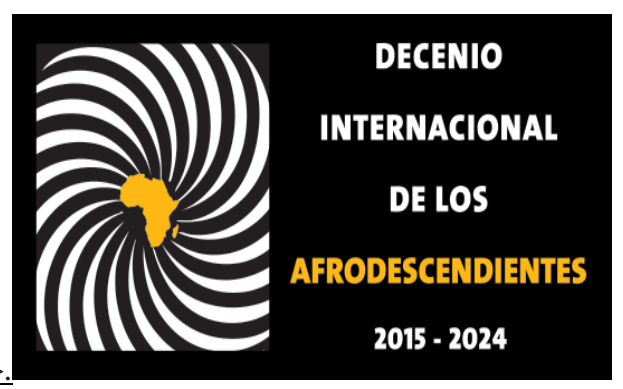

Neste sentido, a década voltada para os afrodescendentes de todo o mundo, destaca o "reconhecimento" que se volta tanto para o direito à igualdade e a não discriminação, como a conscientização da equidade em educação, do levantamento de informações e pesquisas quantitativas para coleta e a participação inclusiva; visando a promoção e efetivação dos parâmetros legais nacionais e internacionais. Além do incentivo aos órgãos competentes para adotar, fortalecer e executar políticas, programas e projetos para a redução da desigualdade nos aspectos humanos, sociais, culturais, civis, políticos e econômicos, bem como a fomentação e organização dos debates públicos e a consulta popular para avaliar os impactos obtidos.

No que tange a "Justiça", há destaque para as temáticas dos tribunais e outros órgãos do judiciário, a permanente busca da sensibilização destes espaços para a adoção de políticas afirmativas reparatórias e a eficácia do julgamento dos crimes de racismo ou a injúria racial. Além disso, aborda-se também a violência policial às comunidades pobres e negras e o fortalecimento do não arquivamento de denúncias relacionado ao assédio sofrido pelos afrodescendentes por gestores e/ou funcionários públicos.

Por fim a Organização das Nações Unidas destaca a importância do "Desenvolvimento" que se refere às estratégias que os países devem proporcionar contra a pobreza através de programas sociais, com a educação visando a não evasão e maior facilidade ao acesso. Bem como, a criação de políticas com maiores investimentos para o fortalecimento da saúde integral da população negra, além da habitação com moradia digna para os cidadãos com uma vida saudável. Em seu livro Política e Educação, Paulo Freire relata o significado de cidadania:

Por outro lado, se faz necessário, neste exercício, relembrar que cidadão significa indivíduo no gozo dos direitos civis e políticos de um Estado e que cidadania tem que ver com a condição de cidadão, quer dizer, com o uso dos direitos e o direito de ter deveres de cidadão (2001b, p.45).

Durante esse período de divulgação da década internacional dos afrodescendentes, muitos dos gestores comprometeram-se pela implementação de políticas públicas que visem à amenização das problemáticas que esta comunidade étnica sofre até seu encerramento. Com o olhar da ONU, a 
comunidade internacional reconhece que pessoas negras de todo o mundo demandam de cuidados específicos.

Nesta perspectiva, a problemática que a comunidade negra enfrenta no decorrer de seu histórico varia conforme o país e região em que estes sujeitos se encontram. Porém, independente das circunstâncias locais, sabe-se que estas desigualdades perpassam todo o processo e/ou legado de injustiças cometidas com esse grupo social em todo o mundo.

\section{O CONSELHO MUNICIPAL DA COMUNIDADE NEGRA - COMDESCCON}

Para Munanga (1994:187) é preciso respeitar a identidade dos sujeitos negros, bem como contribuir com a "tomada de consciência de um segmento étnico-racial excluído da participação na sociedade, para a qual contribuiu economicamente, com trabalho gratuito como escravo, e também culturalmente, em todos os tempos na história do Brasil". Nesta perspectiva o município de Rio Grande, desde o dia 10 do mês de novembro do ano de 2003, criou pela Lei 5.824, vinculado a Secretaria de Município da Cidadania e Assistência Social (SMCAS), o Conselho Municipal do Desenvolvimento Social e Cultural da Comunidade Negra (COMDESCCON), visando resgatar a dignidade do povo negro da cidade acima já mencionada.

Este conselho é um órgão de caráter consultivo, normativo, participativo, monitorador, fiscalizador e avaliador das políticas públicas que visem à promoção da igualdade racial e em questões referentes às resoluções da questão social e cultural dos afro-brasileiros, perante as demandas que se apresentam no território. O Conselho Municipal do Negro é composto pela universidade federal, faculdades locais, clubes sociais negros da cidade, núcleos de estudo, grupos de capoeira, representações de matriz africana, diversos movimentos negros locais e movimentos sociais populares do município, além das secretarias de saúde, educação, assistência e cultura.

Figura 2. Logo do Conselho Municipal da Comunidade Negra de Rio Grande - RS.

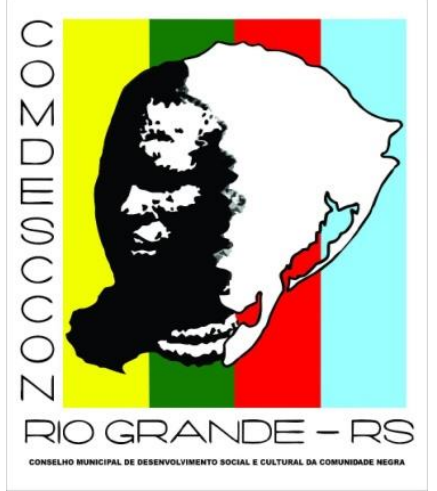

Fonte: 〈http://comdesccon.webnode.com>. 
Destinado a garantir a população negra do município do Rio Grande a efetivação da equidade e a intervenção de direitos coletivos e individuais, o Conselho Municipal do Desenvolvimento Social e Cultural da Comunidade Negra (COMDESCCON) traz em seu artigo $2^{\circ}$ da Lei 5.824 que o cria; sete atribuições:

I. Formular diretrizes e promover atividades que visem à defesa dos direitos da comunidade negra, à eliminação das discriminações raciais contra qualquer grupo humano, sejam a nível público ou privado, bem como lutar para conseguir a plena inserção das pessoas negras na vida sócio econômica, política e cultural do município e do estado e do país; II - Assessorar os poderes públicos nas questões específicas que envolvam a comunidade negra, visando a defesa dos seus direitos e interesses; III. desenvolver estudos, debates e pesquisas relativos às problemáticas da comunidade negra; IV. Sugerir medidas que visem assegurar e ampliar os direitos da cidadania da comunidade negra, pela eliminação de práticas e dispositivos discriminatórios; V Fiscalizar e tomar providências para o cumprimento da legislação favorável aos direitos da comunidade negra; VI - Desenvolver projetos próprios que promovam a participação da comunidade negra em todos os níveis de atividade; VII - Apoiar as realizações concernentes à comunidade negra e promover entendimentos e intercâmbios deste Conselho, segundo as normas desta Lei (2003, p.2-3).

Nesta conjuntura, ficou então o COMDESCCON e seus membros responsáveis por articular e fazer a chamativa da comunidade riograndina para a IV Conferência Intermunicipal de Promoção da Igualdade Racial, que ocorreu no domingo, na data de 24 de setembro do ano de 2017, no salão nobre da Prefeitura Municipal do Rio Grande, localizado à Rua Largo Engenheiro João Fernandes Moreira, no centro da cidade.

\section{DA PARTICIPAÇÃO POPULAR, DOS RESULTADOS E UTOPIAS}

A Conferência Intermunicipal de Promoção da Igualdade Racial de Rio Grande - RS deu inicio às $8 \mathrm{~h}$ e 30 min. da manhã, e desde o período matutino já contava com mais de setenta e três (73) inscritos entre os ouvintes e participantes. A iniciativa vai ao encontro do que explicita Cordioli (2001, p. 27) ao relatar que ao "participar também se pratica e aprende, sendo o melhor caminho para o fortalecimento da cidadania, em suas mais diversas possibilidades".

Em seu contexto, essa Conferência se refere às políticas, aos poderes e interesses desiguais, tendo uma capacidade de enfrentamento do racismo e de produção de condições de vida e de saúde 
biopsicossocioambiespiritual $^{3}$ da comunidade negra. A importância de um espaço de decisões coletivas como essa Conferência, vai muito além do reconhecimento das desigualdades étnicoraciais e do racismo institucional como preocupações determinantes das questões que cercam o negro do país, haja visto que o principal intuito é o incentivo à promoção da equidade. Para o patrono da educação brasileira e Faundez a luta por libertação:

É um fato profundamente pedagógico, e me arriscaria a dizer que é também uma espécie de psicanálise histórica, ideológica, cultural política, social, em que o divã do psicanalista é substituído pelo campo de luta, pelo engajamento na luta, pelo processo de afirmação do colonizado enquanto não mais colonizado, ou das classes dominadas libertando-se (FREIRE; FAUNDEZ, 2017, p.162-163).

O racismo produz resultados em todos os aspectos desiguais que os sujeitos sofrem, aliás, são os afrodescendentes, ainda hoje, os protagonistas do não acesso aos espaços significativos. Sabe-se que as relações sociais são influenciadas pela participação popular através das normas culturais, lutas sociais e a diversidade de ideias. O resultado da troca e transmissão de saberes, bem como das vivências individuais e coletivas, aliados às visões de mundo e modos de agir específicas influenciam a luta do movimento negro até os dias atuais.

A inclusão das pautas étnicas, relacionadas aos negros no Brasil, em instituições de poder como Escola e Estado, perpassa a atuação do movimento negro em diferentes espaços sociopolíticos. Portanto, cabe à consideração de Brose (2007, p. 229) acerca da lenta e gradual construção da democracia, observado que a população negra ainda não acessa direitos fundamentais, embora tenham havidos avanços significativos, conquistados pela luta e resistência dos movimentos sociais populares.

Neste sentido, a atual prática de classificação binária pelas ciências sociais de uma sociedade como sendo autoritária ou democrática de um dia para o outro, na concepção mínima de que a realização ou não de eleições constitui critério suficiente para declarar a democratização, mostra-se insuficiente para o entendimento dos fenômenos sociais que estamos vivenciando desde o início da democratização global pós-1974 (BROSE, 2017, p. 229).

O movimento negro por meio de estratégias de luta que visam à melhoria das relações sociais e raciais; destaca o papel do racismo na produção de condições de vida das crianças, homens e mulheres negras. Com base no exposto; acredita-se que a Conferência Intermunicipal de

\footnotetext{
3 Terminologia adotada recentemente pela Pedagogia Cosmocena em que as dimensões integradoras do ser humano (biológicas, psicológicas, sociológicas, ambientais e espirituais) não são pensadas de formas individuais, compondo assim um único sentido e relação.
} 
Promoção da Igualdade Racial de Rio Grande - RS constituiu-se como um espaço educativo capaz de conduzir à participação da população negra e não negra na elaboração de políticas públicas. Corrobora com essa concepção Cordioli (2001, p. 27) ao afirmar que: "um processo participativo implica em uma aprendizagem mútua, envolvendo todos os que possam contribuir, seja conceitualmente, seja pela sua experiência, assim como os que irão estar à frente da execução das ideias geradas".

Nessa perspectiva, na conferência, as propostas foram discutidas entre todos os delegados que estavam na plenária, bem como alteradas e votadas para serem enviadas de forma a representar as demandas solicitadas e consideradas de validade para encaminhamento à Conferência Nacional, se aprovadas pela Conferência Estadual.

Conforme foi determinado pelo regimento interno nacional, as Conferências deveriam partir da temática obrigatória " $O$ Brasil na década dos afrodescendentes: reconhecimento, justiça e desenvolvimento". Devendo os eixos norteadores conforme o art. $7^{\circ}$ do capítulo III do temário na perspectiva do enfrentamento ao racismo institucional subdividir-se nos seguintes eixos temáticos:

I- Reconhecimento: políticas afirmativas, participação popular, educação básica, ensino superior, cultura, liberdade religiosa e comunicação; II- Justiça: segurança pública, administração penitenciária, justiça, acesso à terra e à cidade e direitos humanos; III- Desenvolvimento: trabalho, desenvolvimento social, juventude, esporte, turismo, meio ambiente e saúde.

No primeiro eixo temático, que trata do "reconhecimento" foi convidado o professor Dr. Airton Fernandes Araújo, ativista e residente na capital do estado, o qual abriu o evento, fazendo provocações à plenária, relacionadas ao racismo institucional e as relações de poder entre brancos e negros que são estabelecidas, fomentando o debate pós a criação do grupo de trabalho do respectivo tema.

No segundo eixo que trata da "Justiça", o evento contou com a presença de acadêmicos do curso de Direito da Universidade Federal do Rio Grande (FURG), que relataram a ausência de profissionais judiciários negros e dos impactos que essa ausência tem, relacionando as injustiças constantemente sofridas pelos afrodescendentes.

Já o terceiro eixo que trata do "desenvolvimento" contou com representantes da Secretaria de Município da Cidadania e Assistência Social (SMCAS) que relataram sobre a intolerância religiosa e da Coordenadoria da Saúde da População Negra da Secretaria de Município de Saúde SMS, que tratou dos desafios para questões de gênero e doenças como anemia falciforme e tuberculose.

A mesa também foi composta por acadêmicos do curso de Pedagogia da Universidade 
Federal do Rio Grande (FURG) tratando da homofobia negra, além dos membros do Núcleo de Estudos Afro-brasileiros e Indígenas (NEABI) da mesma instituição de ensino, tratando sobre os desafios para a juventude negra na área da educação. Vale ressaltar que os eixos temáticos foram apresentados em um painel central e discutidos em grupos de trabalho, assegurando o debate.

Das questões apresentadas à plenária do grupo de trabalho relacionado ao tema do "reconhecimento", apresentado no Quadro de número 1, optou-se pelo envio de: analisar nos partidos políticos a possibilidade da instituição de cotas para afro-indígenas nas candidaturas do processo eleitoral, a recuperação, criação e tombamento dos espaços sociais e culturais dos afroindígenas. Além do incentivo a juventude negra da importância do voto étnico; a obrigatoriedade da participação dos afro-indígenas em todos os conselhos e o incentivo ao feriado nacional do dia 20 de novembro enquanto dia da Consciência Negra, dia de Zumbi dos Palmares.

Quadro 1. Resultado da Conferência Intermunicipal de Promoção da Igualdade Racial de Rio Grande - RS, ocorrida no ano de 2017, para a temática "reconhecimento".

\footnotetext{
Reconhecimento

Instituição de cotas para afro-indígenas nas candidaturas do processo eleitoral municipal.

Recuperação, criação e tombamento dos espaços sociais e culturais dos afro-indígenas.

Defesa do voto étnico.

Participação dos negros e indígenas em todos os conselhos.

Apoio à instituição do feriado nacional e municipal do dia 20 de novembro enquanto dia da Consciência Negra, dia de Zumbi dos Palmares.
}

Fonte: Elaborado pelos autores.

Do grupo de trabalho da temática "Justiça", foram escolhidas as seguintes propostas: formação em nível infantil e fundamental sobre questões de raça e gênero com enfoque na legislação antirracista através da criação de um grupo interdisciplinar de trabalho composto por pedagogos, psicólogos e juristas negros. Também fora deferido o envio da revitalização dos Clubes Sociais Negros como espaços afrocêntricos engajados com a formação da juventude onde seja fornecido apoio psicológico, educacional, cultural e social, e também a criação de um posto de atendimento formado por juristas, psicólogos e assistentes sociais negros para fornecer auxílio jurídico e psicossocial às pessoas que venham a serem vítimas do crime de racismo. A compilação das sugestões colhidas na conferência são apresentadas no Quadro de número 2 abaixo. 
Quadro 2. Resultado da Conferência Intermunicipal de Promoção da Igualdade Racial de Rio Grande - RS, ocorrida no ano de 2017 , para a temática "justiça".

\section{JUSTIÇA}

Formação em nível infantil e fundamental sobre questões de raça e gênero, através da criação de um grupo interdisciplinar de trabalho.

Revitalização de Clubes Sociais Negros como espaços afrocêntricos engajados com a formação da juventude onde seja fornecido apoio psicológico, educacional, cultural e social.

Criação de um posto de atendimento formado por juristas, psicólogos e assistentes sociais negros para pessoas vítimas do crime de racismo.

Fonte: Elaborado pelos autores.

Já no grupo de trabalho relacionado ao "Desenvolvimento", conforme se observa no Quadro 3, como diretriz para a Conferência Estadual apresentou-se: garantir ações afirmativas viabilizando o levantamento de dados da população negra, bem como o deferimento das cotas raciais no setor privado e a criação de um grupo itinerante de educadores com o objetivo de fiscalizar o trabalho do corpo docente das escolas privadas, municipais e estaduais de ensino referente ao cumprimento da lei $10.639 / 2003^{4}$. Além disso, garantir a obrigatoriedade de ensino sobre as relações étnicas raciais nas instituições públicas e privadas de ensino superior e incentivar cursos de qualificação para a população negra através de parcerias com empresas públicas e privadas, viabilizando campanhas informativas sobre a saúde da população negra, em especial a saúde mental.

Quadro 3. Resultado da Conferência Intermunicipal de Promoção da Igualdade Racial de Rio Grande - RS, ocorrida no ano de 2017, para a temática "desenvolvimento":

\section{DESENVOLVIMENTO}

Levantamento de dados da população negra.

Deferimento das cotas raciais no setor privado.

Criação de um grupo itinerante de educadores com o objetivo de fiscalizar o trabalho do corpo docente das escolas privadas, municipais e estaduais de ensino referente ao cumprimento da lei 10.639/2003.

Garantir a obrigatoriedade de ensino sobre as relações étnicas raciais nas instituições públicas e privadas de ensino superior.

Incentivar cursos de qualificação para a população negra através de parcerias com empresas públicas e privadas, viabilizando campanhas informativas sobre a saúde da população negra, em especial a saúde mental.

Fonte: Elaborado pelos autores.

\footnotetext{
${ }^{4}$ Inclui no currículo oficial da rede de ensino a obrigatoriedade da temática "História e Cultura Afro-Brasileira.
} 
Vale ressaltar que terminados os diálogos, cada município ao destacar as demandas e/ou necessidades específicas da comunidade negra local, escolheram as diretrizes e propostas para serem enviadas e defendidas pelos seus delegados na Conferência Estadual com o intuito de serem sancionadas e aprovadas na Conferência Nacional. Nessa projeção, verifica-se o potencial de tais espaços de discussão como propostas dialógicas de promoção do desenvolvimento sociocultural da comunidade negra, por meio da participação ativa na elaboração de políticas públicas que visam à emancipação social negra. Zapata (2001, p. 231) contribui para essa discussão ao considerar que:

A concepção pedagógica aplicada ao desenvolvimento local se estrutura sobre a prática, sobre o fazer, sobre uma aprendizagem ativa, na qual as informações e os conteúdos conceituais e metodológicos se originam na realidade concreta do território, das comunidades e das organizações apoiadas. Assim, a aprendizagem é gerada a partir da reflexão social de dados e informações da realidade, visando à sua transformação. A estratégia está focada no "processo de desenvolvimento local" e não no "processo de apoio", pois este está em função daquele.

Tendo presente a ideia de desenvolvimento local, cabe considerar que são enviadas também as diversas diretrizes e propostas aprovadas pela plenária ao executivo municipal, visando acordo com a Prefeitura para que esta envie em anexo às demandas da sociedade civil para a Câmara dos Vereadores tentando os fazerem acatarem as solicitações da participação popular da Conferência realizada na cidade.

\section{CONSIDERAÇÕES FINAIS}

Através de espaços proporcionados pelas conferências, surgem importantes políticas como as cotas raciais, a inserção da cultura afro-brasileira na $\mathrm{LDB}^{5}$, a política integral de saúde da população negra, dentre tantas outras que foram aprovadas e sancionadas devido ao protagonismo, pertencimento e pressão da participação popular, para com suas necessidades. É evidente que os saberes estão para além da academia, bem como os espaços educativos fora da educação formal, contribuem de forma não menos importante para a execução e formulação de políticas públicas.

Percebe-se com as discussões e/ou debates que as Conferências são o único meio eficaz de fato em que tanto representantes da sociedade civil, quanto representantes do governo buscam introduzir, planejar, monitorar e avaliar as políticas públicas em Conferências anteriores já aprovadas. Com o diálogo entre sociedade e o órgão público, a conferência visa o fortalecimento da política que foi instaurada, auxiliando na formulação e proporcionando a plenária o

\footnotetext{
${ }^{5}$ Lei 9.394 de 20 de Dezembro de 1996, que estabelece as diretrizes e bases da educação nacional.
} 
encaminhamento ao Governo Federal quais as ações mais emergentes que devem ser tomadas para a redução das desigualdades latentes.

Através deste cenário as medidas conjunturais mais importantes são amplamente discutidas e pensadas junto aos diversos saberes e representações da sociedade civil, fortalecendo as bandeiras de lutas que cada grupo carrega. Sabe-se que o racismo é presente no cenário brasileiro e que as Conferências Municipais, Estaduais e Nacionais de Promoção da Igualdade Racial, claramente são consequências do ativismo e militância do Movimento Negro e participação popular de todo o país.

A execução e implementação do poder popular para criar, formular e contribuir com o estado através deste espaço, significa (in) felizmente o reconhecimento do racismo institucional e das desigualdades étnico-raciais. A Conferência Intermunicipal de Promoção da Igualdade Racial da cidade do Rio Grande, bem como todas as que estão sendo realizadas ou já foram no estado do Rio Grande do Sul no ano de 2017, haverão de contribuir de forma significativa com para a IV Conferência Nacional, onde se projeta que poderão proporcionar o acesso às políticas públicas como forma de intervenção para a equidade. 


\section{REFERÊNCIAS}

BACELAR, Jéferson. Etnicidade: ser negro em Salvador. Salvador: Pemba, 1989.

BRANDÃO, C. R. Repensando a Pesquisa Participante. São Paulo: Brasiliense, 1984.

BROSE, Markus Erwin. As origens da participação e da qualidade democrática no Rio Grande do Sul. Revista Katálysis, v. 10, n. 2, 2007. Disponível em: <http://www.scielo.br/pdf/rk/v10n2/a11v10n2〉. Acesso em: 26 jan. 2018.

DE CAMARGO, Ieda; DA SILVA, Mozart L. Educação indígena e afrodescendente: políticas e práticas. Reflexão e Ação, p. 01-07. Disponível em: 〈https://online.unisc.br/seer/index.php/reflex/article/ view/3536/2850>. Acesso em: 23 mar. 2018.

CORDIOLI, Sergio. Enfoque participativo no trabalho com grupos. In: BROSE, Markus. (Org.). Metodologia participativa: uma introdução a 29 instrumentos. Porto Alegre: Tomo Editorial, 2001.

FREIRE, Paulo. Política e Educação. 6. ed. São Paulo: Cortez, 2001 b.

. Pedagogia da Esperança. 3. ed. Rio de Janeiro: Paz e Terra, 1994.

; FAUNDEZ, Antonio. Por uma pedagogia da pergunta. 8. ed. Rio de Janeiro: Paz e Terra, 2017.

MUNANGA, Kabengele; GOMES, Nilma Lino. Para entender o negro no Brasil de hoje: história, realidades, problemas e caminhos. São Paulo: Global; Ação Educativa, 2004.

Identidade, cidadania e democracia: algumas reflexões sobre os discursos anti-racistas no Brasil. In: SPINK, Mary J. (Org.). A cidadania em construção: uma reflexão transdisciplinar. São Paulo: Cortez, 1994. p. 177-187.

ONU, Alto Comissário da Organização para os Direitos Humanos. Década Internacional de Afrodescendentes: reconhecimento, justiça, desenvolvimento. Disponível em: < http://bit.ly/LivretoAfro> Acesso em: 12 jan. 2018.

PEREIRA, Vilmar A. Ecologia Cosmocena: a redefinição do espaço humano no cosmos. Juiz de Fora, MG : Garcia Edizioni, 2016.

RIO GRANDE, Município. Municipal Lei 5.824 de 10 de dezembro de 2003. Cria o Conselho Municipal de Desenvolvimento Social e Cultural da comunidade negra. Anais da... Câmara Municipal. Rio Grande, RS, 2003. Disponível em: https://leismunicipais. com.br/a/rs/r/rio-grande/lei-ordinaria/2003/583/5824/lei-ordinaria-n-5824-2003cria-o-conselho-municipal-de-desenvolvimento-social-e-cultural-da-comunidade-negra.

ZAPATA, Tania. A gestão participativa para o desenvolvimento local. In: BROSE, Markus. (Org). Metodologia participativa: uma introdução a 29 instrumentos. Porto Alegre: Tomo Editorial, 2001. 


\section{RESUMO}

É público e notório que o ferrenho combate à desigualdade racial deveria ser enfrentado por todos os órgãos do governo federal, dos estados e das cidades, porém diante da ineficácia destes poderes para a promoção da igualdade racial surgem as conferências que visam à práxis, ou seja; primeiramente a concepção de que a desigualdade racial existe, bem como a emergente necessidade da execução de políticas públicas eficazes para a redução das desigualdades e posteriormente a não fragilização dos direitos sociais constantemente violentados. Tendo como tema norteador "o Brasil na década de afrodescendentes: reconhecimento, justiça e desenvolvimento" o presente artigo visa analisar os possíveis impactos da participação popular em conjunto com representantes do poder público municipal.

Palavras-Chave: Conferência, Participação Popular. Igualdade Racial.

\section{IMPACTS OF POPULAR PARTICIPATION AT THE IV CONFERENCE OF RACIAL EQUALITY IN RIO GRANDE - RS}

\section{ABSTRACT}

It is public and notorious that the fierce fight against racial inequality should be faced by all the organs of the federal government, the states and the cities, but before the inefficacy of these powers for the promotion of racial equality arise the conferences that aim at the praxis, that is; first of all the conception that racial |inequality exists, as well as the emerging need to implement effective public policies to reduce inequalities and subsequently to not weaken the constantly violated social rights. Having as its guiding theme "Brazil in the decade of Afrodescendants: recognition, justice and development" this article aims to analyze the possible impacts of popular participation together with representatives of municipal public power.

Keywords: Conference, Participation Popular, Racial equality.

\section{IMPACTOS DE LA PARTICIPACIÓN POPULAR EN LA IV CONFERENCIA DE LA IGUALDAD RACIAL EN RIO GRANDE - RS}

\section{RESUMEN}

Es público y notorio que el férreo combate a la desigualdad racial debería ser enfrentado por todos los órganos del gobierno federal, de los estados y de las ciudades, pero ante la ineficacia de estos poderes para la promoción de la igualdad racial surgen las conferencias que apuntan a la praxis, o sea; en primer lugar, la concepción de que la desigualdad racial existe, así como la emergente necesidad de la ejecución de políticas públicas eficaces para la reducción de las desigualdades y posteriormente la no fragilización de los derechos sociales constantemente violados. En el presente artículo se pretende analizar los posibles impactos de la participación popular en conjunto con representantes del poder público municipal.

Palabras clave: Conferencia, Participación Popular, Igualdad Racial. 